\title{
Impact of prenatal environmental stress on cortical development
}

\author{
Seiji Ishii ${ }^{1}$ and Kazue Hashimoto-Torii ${ }^{1,2,3 *}$ \\ ${ }^{1}$ Center for Neuroscience Research, Children's National Medical Center, Children's Research Institute, Washington, DC, \\ USA, ${ }^{2}$ Department of Pediatrics, Pharmacology and Physiology, School of Medicine and Health Sciences, The George \\ Washington University, Washington, DC, USA, ${ }^{3}$ Department of Neurobiology, School of Medicine, Kavli Institute for \\ Neuroscience, Yale University, New Haven, CT, USA
}

\section{OPEN ACCESS}

Edited by:

Takeshi Kawauchi, Keio University School of Medicine/PRESTO, JST, Japan

Reviewed by: Richard S. Nowakowski, Florida State University, USA Mladen-Roko Rasin, Robert Wood Johnson Medical School, USA

Eric C. Olson State University of New York Upstate Medical University, USA

*Correspondence: Kazue Hashimoto-Torii, Center for Neuroscience Research, Children's Research Institute, Children's National Medical Center, and Department of Pediatrics, Pharmacology and Physiology, The George Washington University School of Medicine and Health Sciences, 111 Michigan Avenue N.W., M7633, Washington, DC, 20010-2970, USA KHTori@childrensnational.org

Received: 01 February 2015 Accepted: 13 May 2015 Published: 27 May 2015

Citation: Ishii S and Hashimoto-Torii K (2015) Impact of prenatal environmental stress on cortical development.

Front. Cell. Neurosci. 9:207. doi: 10.3389/fncel.2015.00207
Prenatal exposure of the developing brain to various types of environmental stress increases susceptibility to neuropsychiatric disorders such as autism, attention deficit hyperactivity disorder and schizophrenia. Given that even subtle perturbations by prenatal environmental stress in the cerebral cortex impair the cognitive and memory functions, this review focuses on underlying molecular mechanisms of pathological cortical development. We especially highlight recent works that utilized animal exposure models, human specimens or/and induced Pluripotent Stem (iPS) cells to demonstrate: (1) molecular mechanisms shared by various types of environmental stressors, (2) the mechanisms by which the affected extracortical tissues indirectly impact the cortical development and function, and (3) interaction between prenatal environmental stress and the genetic predisposition of neuropsychiatric disorders. Finally, we discuss current challenges for achieving a comprehensive understanding of the role of environmentally disturbed molecular expressions in cortical maldevelopment, knowledge of which may eventually facilitate discovery of interventions for prenatal environment-linked neuropsychiatric disorders.

Keywords: cortical development, prenatal environmental stress, alcohol, autism, schizophrenia, maternal immune activation, gene-environment interaction, iPS cells

\section{Introduction}

The development of the cerebral cortex consists of very intricate multifaceted steps including proliferation/differentiation of neural progenitor cells, neuronal migration and maturation (Whitford et al., 2002; Kriegstein and Noctor, 2004; Kriegstein et al., 2006; Ayala et al., 2007; Barnes and Polleux, 2009; Rakic, 2009; Rakic et al., 2009; Evsyukova et al., 2013; Lewis et al., 2013), and it can be impaired by exposure to environmental stress (Ben-Ari, 2008; Deverman and Patterson, 2009; Thompson et al., 2009). Even subtle disturbances in the development of the cerebral cortex impair cognitive and memory functions (Berger-Sweeney and Hohmann, 1997; Arnsten, 2009). Accordingly, ever increasing attention is being paid to understanding the underlying non-genomic alterations thought to govern impairment.

Alcohol is known as one of the most prevalent prenatal environmental stress, and prenatal alcohol exposure-linked impairments are categorized under the term "Fetal Alcohol Spectrum

Abbreviations: iPS cells, induced Pluripotent Stem cells; FASD, fetal alcohol spectrum disorder; HSP(s), Heat Shock Protein(s); HSF1, Heat Shock Factor 1; MIA, maternal immune activation; IL-6, interleukin-6; DISC1, disrupted-inschizophrenia-1. 
Disorder (FASD)." FASD patients show higher rates of comorbidity with various types of neuropsychiatric problems, such as attention deficit hyperactivity disorder (ADHD) and epilepsy (Mattson and Riley, 1998). Histological analysis using postmortem tissues from FASD patients documented various anomalies in the brain, including heterotopias, microcephaly, hydrocephaly, and agenesis of the corpus callosum (Clarren and Smith, 1978; Roebuck et al., 1998; Muralidharan et al., 2013). Many of these morphological phenotypes, as well as behavioral phenotypes of human patients, have been reproduced by non-human primate, rodent and other vertebrate models of fetal alcohol exposure, and therefore, these animal models have been used for understanding etiology of FASD and other health problems linked to prenatal alcohol exposure (Miller and Nowakowski, 1991; Kelly et al., 2009; Wilson and Cudd, 2011; Patten et al., 2014). Furthermore, these animal studies found that fetal alcohol exposure particularly affects the development of the cerebral cortex, in multiple cellular events including proliferation, differentiation, apoptosis, migration, synaptogenesis and dendritogenesis, depending on the regimens and timing of exposure (Lindsley et al., 2006; Thompson et al., 2009; Miranda, 2012).

Similarly, clinical and epidemiological studies identified a variety of environmental stressors, exposure to which increases the risk of neuropsychiatric diseases (Schmitt et al., 2014). Importantly, rodent and non-human primate models of prenatal exposure to those environmental factors, including hypoxia (Golan et al., 2009; Howell and Pillai, 2014), drugs such as cocaine (Gressens et al., 1992; Cabrera-Vera et al., 2000; Stanwood et al., 2001; Lidow and Song, 2001a,b; Crandall et al., 2004; Thompson et al., 2009), and heavy metals such as methylmercury (Kakita et al., 2001; Hashimoto-Torii et al., 2014), have shown that these factors cause similar structural anomalies in the cortex as well as similar abnormal behaviors (Thompson et al., 2009). These findings imply that different environmental challenges provide common impacts on cortical development, thereby resulting in similar endophenotypes.

Here, we review recent publications that found molecular mechanisms underlying pathological cortical development elicited by exposure to prenatal environmental stress and discuss how various types of prenatal environmental stress similarly affect cortical development and increase the risk of neuropsychiatric disorders.

\section{Early Response Genes That Protect or Disturb Cortical Development under the Conditions of Exposure to Environmental Stress}

Based on recent findings using prokaryotes, genes that respond (either by increase or decrease of expression) to environmental stress can be classified mainly into two groups (Mitchell et al., 2009; Levine et al., 2013; Young et al., 2013). The first group consists of genes that exhibit altered expression immediately upon exposure to multiple types of environmental insult. The second group consists of genes that exhibit altered expression profiles only upon exposure to specific types of environmental stress and are generally altered gradually post exposure. Thus, orchestrated changes in the activities of these two types of genes are likely to occur in developing cortices. The following section focuses on the first group of genes that immediately respond to environmental stress and may lead to common endophenotypes (Gluckman and Hanson, 2004), discussing how these genes change the molecular landscape of cortical development and contribute to the pathogenesis elicited by prenatal environmental stress.

\section{Stress Responsive Signaling}

The cellular stress activates multiple signaling pathways that are well-positioned to help restore homeostasis upon sudden environmental changes, or, in the long run, enforce a new gene expression program so cells can tolerate the new environment. These signaling pathways and genes include molecular chaperone encoding genes, genes involved in the unfolded protein response, Mitogen-Activated Protein Kinase (MAPK) and Growth Arrest and DNA Damage 45 (GADD45) signaling pathways (Yang et al., 2009). The Heat Shock Protein (HSP) pathway is a major molecular chaperone signaling pathway, the activation of which has been identified as one of immediate molecular responses to various types of environmental stress, including alcohol, heat, heavy metals and viral infection (Nollen and Morimoto, 2002; Hashimoto-Torii et al., 2011, 2014).

Our recent study using knockout mice of Heat shock factor 1 (Hsf1), a canonical transcription factor that controls transcription of $H s p$ genes revealed that activation of this signaling is required to reduce the risk of cortical malformation, such as heterotopias and small size of the cortex, upon prenatal exposure to various types of environmental stress, thereby reducing susceptibility to epilepsy (Hashimoto-Torii et al., 2014). Histological analysis immediately after prenatal stress exposure revealed that the increase of these cortical malformations in Hsf1 knockout mice is due to the increase of cell death and suspension of cell cycling, suggesting Hsf1's roles in cellular protection against environmental stress. Interestingly, the canonical downstream targets of $H s f 1$, Hsps mediate proapoptotic effects of $H s f 1$ but not the effects on cell cycling (Figure 1). El Fatimy et al. (2014) showed that, many cortical genes that are critically involved in the control of cell cycling/proliferation and the neuronal migration are under the control of $H s f 1$ and the family gene Hsf2. Thus, the activation of HSF1 immediately alters expressions of various types of genes to protect the embryonic cortex from environmental stress.

Another example of a stress responsive transcriptional factor that protects the fetal brain from prenatal environmental stress is Nuclear Factor Erythroid 2-Related Factor 2 (Nfe2l2/Nrf2). The transcriptional activity is increased in response to such as alcohol (Narasimhan et al., 2011), kainate induced excitotoxic damage (Rojo et al., 2008a) and hydrogen peroxide induced oxidative stress (Rojo et al., 2008b). The target genes include multiple genes that encode antioxidant proteins (Dong et al., 2008; Muramatsu et al., 2013). Prenatal exposure to methamphetamine (speed) plus Nrf2 loss of function lead to reduced motor activity, smaller body weight etc. in the offspring (Ramkissoon and Wells, 2013). 


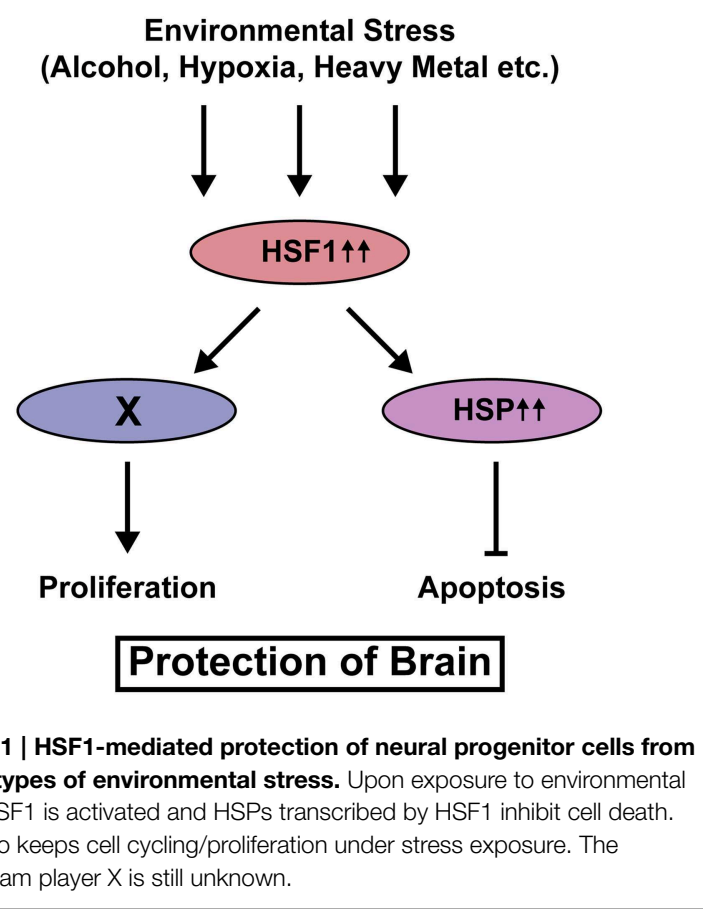

FIGURE 1 | HSF1-mediated protection of neural progenitor cells from various types of environmental stress. Upon exposure to environmental stress, HSF1 is activated and HSPs transcribed by HSF1 inhibit cell death. HSF1 also keeps cell cycling/proliferation under stress exposure. The downstream player $X$ is still unknown.

Interestingly, the gender dependent differences were observed in the severity of the phenotypes.

These lines of evidence suggest that multiple cellular mechanisms provoked by the stress response genes act to ensure fetal cortical tolerance to environmental stress, and thus decrease the prevalence and severity of ensuing neuropsychiatric diseases (Hashimoto-Torii et al., 2014).

\section{MicroRNAs}

Post-transcriptional controls have been demonstrated to be critically involved in the control of normal cortical development (Grabowski, 2011; DeBoer et al., 2013; Yano et al., 2015). MicroRNAs (miRNAs) are non-coding RNAs that are involved in post-transcriptional regulation of the expression of a wide variety of genes (Ambros, 2004). Because of their nature as short RNAs for post-transcriptional regulation of genes, they are likely to change the molecular landscape of the cell immediately and temporally in response to environmental challenges (Leung and Sharp, 2010).

In a comprehensive miRNA profiling study using a neurosphere model of alcohol exposure, Miranda and his colleagues found a reduction in expressions of $m i R-21, m i R-335$, $m i R-9$, and $m i R-15324 \mathrm{~h}$ after exposure (Sathyan et al., 2007).

MiR-9 knockout mouse displays smaller brain size (Shibata et al., 2011). The analysis of those embryonic brains suggested that impaired proliferation and differentiation of neural progenitor cells in stage dependent manner may lead to the smaller brain. Consistent with this in vivo observation, miR-9 knockdown inhibited the proliferation and promoted the migration of the neural progenitor cells in vitro (Delaloy et al., 2010). The control of these biological events by miR-9 may be mediated by controlling expression levels of the downstream targets such as Forkhead box G1 (Foxg1/Bf1) (Shibata et al.,
2008, 2011), embryonic lethal, abnormal vision, Drosophila like 2 (Elavl2/HuB) (Sathyan et al., 2007), Fibroblast growth factor receptor 1 (Fgfr1) (Pappalardo-Carter et al., 2013), Forkhead box P2 (Foxp2) (Pappalardo-Carter et al., 2013), Stathmin 1 (Stmn1) (Delaloy et al., 2010), Nuclear receptor subfamily 2, group E, member 1 (Nr2e1/Tlx) (Zhao et al., 2009; Shibata et al., 2011), Inhibitor of DNA binding 4 (Id4) (Shibata et al., 2008), Paired box 6 (Pax6) (Shibata et al., 2011), Meis homeobox 2 (Meis2) (Shibata et al., 2011), GS homeobox 2 (Gsh2) (Shibata et al., 2011), Islet1 (Isl1) (Shibata et al., 2011), RE1-silencing transcription factor (Rest) (Packer et al., 2008), and Actin-like 6A (Actl6a/BAF53a) (Yoo et al., 2009). Thus, reduced expression of $m i R-9$ by alcohol exposure is also likely to inhibit those events by the similar mechanism. The miR-153 and miR-21 also similarly control the cellular proliferation (Zhong et al., 2012; Wu et al., 2013).

Reduction of $m i R-9$ expression and the target gene expressions in the zebrafish whole-embryo (Tal et al., 2012) and the embryonic forebrain (Pappalardo-Carter et al., 2013) exposed to alcohol also supports this hypothesis. However, in the conditions of exposure to different contexts of maternal stress induced by such as restraint of the body and forced swimming, expression of miR-9 was increased in the brain of offspring (Zucchi et al., 2013). Similarly, the expression of $m i R-21$ has also been reported to be increased in the different ambience, such as in the mouse brain exposed to ionizing radiation (Shi et al., 2012a), in the endothelial cells under the exposure to shear stress (Weber et al., 2010), and in the embryonic fibroblasts exposed to arsenite (Ling et al., 2012). The expression of $m i R-153$ is also upregulated by hydrogen peroxidase induced oxidative stress (Narasimhan et al., 2014) and nicotine exposure (Tsai et al., 2014). These lines of evidence indicate that the microRNAs are susceptible to the environmental changes and that the overall changes of various types of microRNAs may determine the phenotypes specific to types/regimens of the environmental stress exposure. The fact that miR-335 knockdown reverses the effects of miR-21 knockdown in the cell proliferation and death also supports this possibility (Sathyan et al., 2007).

\section{Maternal, Placental, and Extracortical Tissues Exhibit Indirect Effects as a Result of Environmental Stress}

Beside direct molecular changes within embryonic cortical cells, evidences exist that indirect impacts of environmental stress from maternal, placental, and other extracortical tissues exert a critical influence on cortical development (Velasquez et al., 2013).

Maternal infection is well defined by epidemiological studies as a risk factor for neurodevelopmental disorders such as autism and schizophrenia (Hagberg et al., 2012; Depino, 2013; Meldrum et al., 2013). Mouse offspring that have been exposed to maternal infection display abnormalities reminiscent of the behavioral, histological, and molecular characteristics of autism (Patterson, 2011), while fetal brain infection does not cause these abnormalities (Meldrum et al., 2013). Mouse offspring exposed to maternal immune activation (MIA), which is elicited by poly-riboinosinic-polyribocytidylic acid or lipopolysaccharide, 
also reproduce the behavioral and histological abnormalities of autism (Meyer et al., 2006; Smith et al., 2007; Hsiao et al., 2012; Carpentier et al., 2013), suggesting that activation of maternal immune system triggered by infection is critical for manifestation of deficits. These early findings have proven MIA model useful in the investigation of the molecular mechanisms at play in unraveling maternal effects on the pathophysiology of autism.

Smith et al. (2007) demonstrated that a proinflammatory cytokine interleukin-6 (IL-6) supplied from the maternal tissues might mediate the MIA effects on the fetal cortex. A single maternal injection of IL- 6 in the middle of corticogenesis causes deficits in prepulse inhibition and lateral inhibition in the offspring (Smith et al., 2007), both of which are linked to autism and schizophrenia (Solomon et al., 1981; Wynn et al., 2004; Bertone et al., 2005; Perry et al., 2007). They also demonstrated that inhibition of IL- 6 by application of the antibody or using the knockout dam, significantly ameliorated such as cognitive and exploratory deficits in mouse offspring exposed to MIA (Smith et al., 2007). The gene expression profiles were also reversed by inhibition of IL-6 in the cortices of the MIA offspring. These results provided evidence that IL- 6 may owe the indirect effects of MIA on fetal cortical development.

Indirect effects of MIA on cortical development may also involve the effects from gastrointestinal tissues of offspring. Autism is often associated with gastrointestinal barrier defects (Buie et al., 2010; Coury et al., 2012), and rodent MIA models reproduce these defects (Hsiao et al,, 2013). Hsiao and colleagues made an interesting observation that probiotic treatment of gastrointestinal barrier defects improved behavioral abnormalities such as anxiety-like behavior, decreased prepulse inhibition, and deficits in ultrasonic vocal communication in the MIA offspring. Their study also suggested the possibility that gastrointestinal barrier deficit-induced increase of serum metabolites such as 4-ethylphenylsulfate, indolepyruvate, glycolate, imidazole propionate, and $\mathrm{N}$-acetylserine, may contribute to behavior abnormality in the MIA offspring (Hsiao et al., 2013). Of these, the most dramatically affected metabolite, 4-ethylphenylsulfate, has been known as a uremic toxin, and the administration of this metabolite induces anxiety-like behavior in the mouse (Hsiao et al., 2013). As a recent study suggested the link between the uremic toxin and the depression in the chronic kidney disease (Hsu et al., 2013), the 4-ethylphenylsulfate in serum may be the common factor that affects the brain function in various pathophysiological conditions.

Serotonin derived from placenta may also indirectly affect embryonic brain development. Recent studies demonstrated that the placenta is the major source of serotonin at early embryonic stage, while the dorsal raphe nuclei in the hindbrain take over from late embryonic stage to adulthood (Bonnin et al., 2011). Abnormal serotonin levels in the brain have been linked to autism (Chugani et al., 1999; Whitaker-Azmitia, 2001; Gaspar et al., 2003), and the role of serotonin in the normal development of thalamocortical projections also has been reported (Bonnin et al., 2007). In addition, it has been demonstrated that prenatal intake of selective serotonin reuptake inhibitors increases the risk of cognitive impairment in mouse progeny (Smit-Rigter et al., 2012; Kinast et al., 2013). Importantly, serotonin level is lower in the cortices of the offspring exposed to environmental stress such as maternal infection (Fatemi et al., 2008; Wang et al., 2009) and cocaine (Cabrera-Vera et al., 2000). Therefore, environmental stressors may indirectly affect the cortical development as a result of disruption in the synthesis/release of serotonin in/from the placenta (Velasquez et al., 2013).

\section{Interaction between a Susceptible Genotype and Environmental Risk Factors}

Genome wide association studies have shown a polygenic component contributes to the risk of schizophrenia and autism (Purcell et al., 2014). Similarly, many epidemiological studies as well as the aforementioned results from studies of animal exposure models have shown these disorders also include a "polyepigenetic" component that is influenced by various types of environmental stress (Weinberger, 1987; Caspi and Moffitt, 2006; Ben-Ari, 2008; van Os et al., 2010; Bregant et al., 2013). However, just how the polyepigenetic component increases the risk of disease manifestation by interacting with polygenic component is largely unknown.

One relatively new approach to help answering this question is the use of induced Pluripotent Stem (iPS) cells taken from subjects diagnosed with polygenic diseases such as schizophrenia or autism. iPS cells are not only becoming useful tools to obtain functional human cortical neurons (Mariani et al., 2012; Shi et al., 2012b; Espuny-Camacho et al., 2013; Lancaster et al., 2013) for understanding the pathogenesis of disease, but are also being utilized for drug screening (Han et al., 2011). To examine potential interactions between genetic predisposition and the environmental risk factors, we recently used iPS cells derived from schizophrenia patients, and exposed the differentiated neural progenitor cells to environmental stress including alcohol, methylmercury and hydrogen peroxide. Single cell RNA detection revealed augmented cell-to-cell variable activation of HSF1-HSP signaling in the schizophrenia patients' neural progenitor cells, individual cell lines of which carry different genetic risks for schizophrenia (Figure 2). This finding suggests that variable responses of HSF1-HSP signaling among a population of neural progenitor cells exposed to environmental

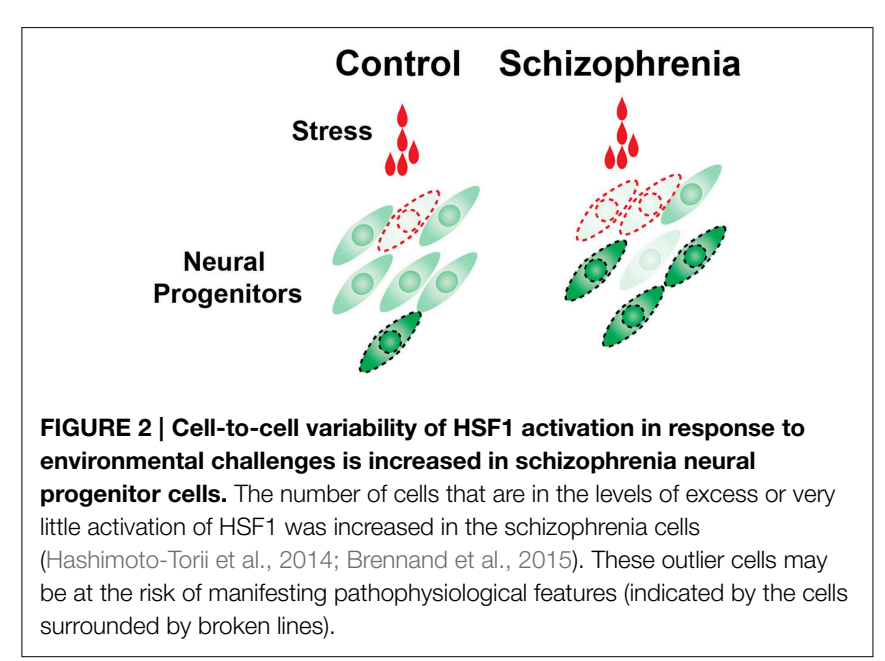


stress is predetermined by genetic predisposition and may increase the risk of the onset of schizophrenia as well as other neuropsychiatric diseases (Hashimoto-Torii et al., 2014; Brennand et al., 2015).

Using Disrupted-in-schizophrenia-1 gene (Disc1) mutant mice combined with MIA, in vivo evidence for the interaction of gene and prenatal environment in the pathogenesis of schizophrenia and depression was also provided. The Discl is one of the risk genes for psychiatric disorders such as schizophrenia and mood disorders (St Clair et al., 1990; Millar et al., 2000). The transgenic mice expressing the dominant negative form of Disc1 that was found in the patient (Millar et al., 2000), displayed hyperactivity and impaired social interaction (Pletnikov et al., 2008). When this transgenic mouse was subjected to MIA, neurobehavioral phenotypes such as anxiety, depression-like behavior, and a decrease in social interaction and an increase in aggressiveness were unraveled (Abazyan et al., 2010). Two other Disc1 mutant mouse lines with point mutations at Q31L and L100P, which show schizophrenia and depression related phenotypes, respectively (Clapcote et al., 2007), were also subjected to MIA. MIA exposure augmented the impairment in prepulse inhibition, lateral inhibition, spatial object recognition, and social motivation of those Disc1 mutant mice (Lipina et al., 2013). Importantly, the production of IL-6 was concomitantly increased by the combination of Disc1 mutations and the MIA in the fetal mouse brains (Lipina et al., 2013). Thus, these mouse models that combine Disc1 mutation and MIA will become powerful models for understanding the molecular mechanisms underlying interactions between the gene and prenatal environmental factors that increase the risk of the psychiatric diseases.

\section{Outlook}

As outlined in this review, research on polyepigenetic mechanisms associated with many types of environmental stress that disturb cortical development and on potential prophylactic or preventative interventions of these disturbances are just beginning to emerge. To further facilitate this type of

\section{References}

Abazyan, B., Nomura, J., Kannan, G., Ishizuka, K., Tamashiro, K. L., Nucifora, F., et al. (2010). Prenatal interaction of mutant DISC1 and immune activation produces adult psychopathology. Biol. Psychiatry 68, 1172-1181. doi: 10.1016/j.biopsych.2010.09.022

Ambros, V. (2004). The functions of animal microRNAs. Nature 431, 350-355. doi: 10.1038 /nature 02871

Arnsten, A. F. (2009). Stress signalling pathways that impair prefrontal cortex structure and function. Nat. Rev. Neurosci. 10, 410-422. doi: 10.1038/nrn2648

Ayala, R., Shu, T., and Tsai, L. H. (2007). Trekking across the brain: the journey of neuronal migration. Cell 128, 29-43. doi: 10.1016/j.cell.2006. 12.021

Barnes, A. P., and Polleux, F. (2009). Establishment of axon-dendrite polarity in developing neurons. Annu. Rev. Neurosci. 32, 347-381. doi: 10.1146/annurev.neuro.31.060407.125536

Ben-Ari, Y. (2008). Neuro-archaeology: pre-symptomatic architecture and signature of neurological disorders. Trends Neurosci. 31, 626-636. doi: 10.1016/j.tins.2008.09.002 research, patient-derived iPS cells will become one of several powerful tools. Although there are a number of limitations in their use, easy application of environmental stress and the potential for high throughput analysis substantiate their usefulness. Challenges include: (1) limited availability of iPS cell lines that are fully characterized; (2) lack of validated differentiation protocols for specific types of neurons; and (3) lack of validated in vivo approaches (e.g., efficient transplantation methods to animal models, etc.) that allow observation of the iPS cells during cortical development.

A type of the environmental stress can lead to various phenotypes in the cerebral cortex, however, this variability cannot be explained exclusively by different regimens of exposure. Recent studies have revealed potential factors that may affect the resultant phenotypes, including gender (Mooney and Varlinskaya, 2011; Ramkissoon and Wells, 2013) and probabilistic molecular responses of individual cells to the environmental stress (Hashimoto-Torii et al., 2014) (Figure 2) etc. Thus, the next important questions will be: (1) if such molecular differences of individual cells elicited by environmental stress are sustained for long periods of time and ultimately result in altered cortical function, and (2) which molecules mediate the gender specific effects of prenatal environmental stress.

Another recent interesting observation that needs to be addressed at the molecular level is the transgenerational effects of prenatal exposure to environmental stress, as reported in the cases of alcohol (Govorko et al., 2012). This observation opens up a whole new field of research that might eventually lead to an understanding of why FASD and other environment-linked disorders show familial and geographical linkages.

\section{Acknowledgments}

We thank Miki Masuda, Drs. Alexander I. Son, and Masaaki Torii for their comments on the manuscript. We also thank NIH/NIAAA R00AA1838705, CTSI-CN, NARSAD/Scott-Gentle Foundation and ABMRF for their respective support.

Berger-Sweeney, J., and Hohmann, C. F. (1997). Behavioral consequences of abnormal cortical development: insights into developmental disabilities. Behav. Brain Res. 86, 121-142. doi: 10.1016/S0166-4328(96)02251-6

Bertone, A., Mottron, L., Jelenic, P., and Faubert, J. (2005). Enhanced and diminished visuo-spatial information processing in autism depends on stimulus complexity. Brain 128, 2430-2441. doi: 10.1093/brain/awh561

Bonnin, A., Goeden, N., Chen, K., Wilson, M. L., King, J., Shih, J. C., et al. (2011). A transient placental source of serotonin for the fetal forebrain. Nature 472, 347-350. doi: 10.1038/nature09972

Bonnin, A., Torii, M., Wang, L., Rakic, P., and Levitt, P. (2007). Serotonin modulates the response of embryonic thalamocortical axons to netrin-1. Nat. Neurosci. 10, 588-597. doi: 10.1038/nn1896

Bregant, T., Rados, M., Vasung, L., Derganc, M., Evans, A. C., Neubauer, D., et al. (2013). Region-specific reduction in brain volume in young adults with perinatal hypoxic-ischaemic encephalopathy. Eur. J. Paediatr. Neurol. 17, 608-614. doi: 10.1016/j.ejpn.2013.05.005

Brennand, K., Savas, J. N., Kim, Y., Tran, N., Simone, A., Hashimoto-Torii, K., et al. (2015). Phenotypic differences in hiPSC NPCs derived from patients with schizophrenia. Mol. Psychiatry 20, 361-368. doi: 10.1038/mp.2014.22 
Buie, T., Campbell, D. B., Fuchs, G. J. III, Furuta, G. T., Levy, J., Vandewater, J., et al. (2010). Evaluation, diagnosis, and treatment of gastrointestinal disorders in individuals with ASDs: a consensus report. Pediatrics 125(Suppl. 1), S1-S18. doi: 10.1542/peds.2009-1878c

Cabrera-Vera, T. M., Garcia, F., Pinto, W., and Battaglia, G. (2000). Neurochemical changes in brain serotonin neurons in immature and adult offspring prenatally exposed to cocaine. Brain Res. 870, 1-9. doi: 10.1016/S0006-8993(00) 02382-9

Carpentier, P. A., Haditsch, U., Braun, A. E., Cantu, A. V., Moon, H. M., Price, R. O., et al. (2013). Stereotypical alterations in cortical patterning are associated with maternal illness-induced placental dysfunction. J. Neurosci. 33, 16874-16888. doi: 10.1523/JNEUROSCI.4654-12.2013

Caspi, A., and Moffitt, T. E. (2006). Gene-environment interactions in psychiatry: joining forces with neuroscience. Nat. Rev. Neurosci. 7, 583-590. doi: 10.1038/nrn1925

Chugani, D. C., Muzik, O., Behen, M., Rothermel, R., Janisse, J. J., Lee, J., et al. (1999). Developmental changes in brain serotonin synthesis capacity in autistic and nonautistic children. Ann. Neurol. 45, 287-295.

Clapcote, S. J., Lipina, T. V., Millar, J. K., Mackie, S., Christie, S., Ogawa, F., et al. (2007). Behavioral phenotypes of Disc1 missense mutations in mice. Neuron 54, 387-402. doi: 10.1016/j.neuron.2007.04.015

Clarren, S. K., and Smith, D. W. (1978). The fetal alcohol syndrome. N. Engl. J. Med. 298, 1063-1067. doi: 10.1056/NEJM197805112981906

Coury, D. L., Ashwood, P., Fasano, A., Fuchs, G., Geraghty, M., Kaul, A., et al. (2012). Gastrointestinal conditions in children with autism spectrum disorder: developing a research agenda. Pediatrics 130(Suppl. 2), S160-S168. doi: 10.1542/peds.2012-0900n

Crandall, J. E., Hackett, H. E., Tobet, S. A., Kosofsky, B. E., and Bhide, P. G. (2004). Cocaine exposure decreases GABA neuron migration from the ganglionic eminence to the cerebral cortex in embryonic mice. Cereb. Cortex 14, 665-675. doi: 10.1093/cercor/bhh027

DeBoer, E. M., Kraushar, M. L., Hart, R. P., and Rasin, M. R. (2013). Post-transcriptional regulatory elements and spatiotemporal specification of neocortical stem cells and projection neurons. Neuroscience 248, 499-528. doi: 10.1016/j.neuroscience.2013.05.042

Delaloy, C., Liu, L., Lee, J. A., Su, H., Shen, F., Yang, G. Y., et al. (2010). MicroRNA-9 coordinates proliferation and migration of human embryonic stem cell-derived neural progenitors. Cell Stem Cell 6, 323-335. doi: 10.1016/j.stem.2010.02.015

Depino, A. M. (2013). Peripheral and central inflammation in autism spectrum disorders. Mol. Cell. Neurosci. 53, 69-76. doi: 10.1016/j.mcn.2012.10.003

Deverman, B. E., and Patterson, P. H. (2009). Cytokines and CNS development. Neuron 64, 61-78. doi: 10.1016/j.neuron.2009.09.002

Dong, J., Sulik, K. K., and Chen, S. Y. (2008). Nrf2-mediated transcriptional induction of antioxidant response in mouse embryos exposed to ethanol in vivo: implications for the prevention of fetal alcohol spectrum disorders. Antioxid. Redox Signal. 10, 2023-2033. doi: 10.1089/ars.2007.2019

El Fatimy, R., Miozzo, F., Le Mouel, A., Abane, R., Schwendimann, L., SaberanDjoneidi, D., et al. (2014). Heat shock factor 2 is a stress-responsive mediator of neuronal migration defects in models of fetal alcohol syndrome. EMBO Mol. Med. 6, 1043-1061. doi: 10.15252/emmm.201303311

Espuny-Camacho, I., Michelsen, K. A., Gall, D., Linaro, D., Hasche, A., Bonnefont, J., et al. (2013). Pyramidal neurons derived from human pluripotent stem cells integrate efficiently into mouse brain circuits in vivo. Neuron $77,440-456$. doi: 10.1016/j.neuron.2012.12.011

Evsyukova, I., Plestant, C., and Anton, E. S. (2013). Integrative mechanisms of oriented neuronal migration in the developing brain. Annu. Rev. Cell Dev. Biol. 29, 299-353. doi: 10.1146/annurev-cellbio-101512-122400

Fatemi, S. H., Reutiman, T. J., Folsom, T. D., Huang, H., Oishi, K., Mori, S., et al. (2008). Maternal infection leads to abnormal gene regulation and brain atrophy in mouse offspring: implications for genesis of neurodevelopmental disorders. Schizophr. Res. 99, 56-70. doi: 10.1016/j.schres.2007.11.018

Gaspar, P., Cases, O., and Maroteaux, L. (2003). The developmental role of serotonin: news from mouse molecular genetics. Nat. Rev. Neurosci. 4, 1002-1012. doi: 10.1038/nrn1256

Gluckman, P. D., and Hanson, M. A. (2004). Living with the past: evolution, development, and patterns of disease. Science 305, 1733-1736. doi: $10.1126 /$ science. 1095292
Golan, M. H., Mane, R., Molczadzki, G., Zuckerman, M., Kaplan-Louson, V., Huleihel, M., et al. (2009). Impaired migration signaling in the hippocampus following prenatal hypoxia. Neuropharmacology 57, 511-522. doi: 10.1016/j.neuropharm.2009.07.028

Govorko, D., Bekdash, R. A., Zhang, C., and Sarkar, D. K. (2012). Male germline transmits fetal alcohol adverse effect on hypothalamic proopiomelanocortin gene across generations. Biol. Psychiatry 72, 378-388. doi: 10.1016/j.biopsych.2012.04.006

Grabowski, P. (2011). Alternative splicing takes shape during neuronal development. Curr. Opin. Genet. Dev. 21, 388-394. doi: 10.1016/j.gde.2011.03.005

Gressens, P., Kosofsky, B. E., and Evrard, P. (1992). Cocaine-induced disturbances of corticogenesis in the developing murine brain. Neurosci. Lett. 140, 113-116. doi: 10.1016/0304-3940(92)90694-3

Hagberg, H., Gressens, P., and Mallard, C. (2012). Inflammation during fetal and neonatal life: implications for neurologic and neuropsychiatric disease in children and adults. Ann. Neurol. 71, 444-457. doi: 10.1002/ana.22620

Han, S. S., Williams, L. A., and Eggan, K. C. (2011). Constructing and deconstructing stem cell models of neurological disease. Neuron 70, 626-644. doi: 10.1016/j.neuron.2011.05.003

Hashimoto-Torii, K., Kawasawa, Y. I., Kuhn, A., and Rakic, P. (2011). Combined transcriptome analysis of fetal human and mouse cerebral cortex exposed to alcohol. Proc. Natl. Acad. Sci. U.S.A. 108, 4212-4217. doi: 10.1073/pnas.1100903108

Hashimoto-Torii, K., Torii, M., Fujimoto, M., Nakai, A., El Fatimy, R., Mezger V., et al. (2014). Roles of heat shock factor 1 in neuronal response to fetal environmental risks and its relevance to brain disorders. Neuron 82, 560-572. doi: 10.1016/j.neuron.2014.03.002

Howell, K. R., and Pillai, A. (2014). Effects of prenatal hypoxia on schizophreniarelated phenotypes in heterozygous reeler mice: a gene $\mathrm{x}$ environment interaction study. Eur. Neuropsychopharmacol. 24, 1324-1336. doi: 10.1016/j.euroneuro.2014.05.011

Hsiao, E. Y., McBride, S. W., Chow, J., Mazmanian, S. K., and Patterson, P. H. (2012). Modeling an autism risk factor in mice leads to permanent immune dysregulation. Proc. Natl. Acad. Sci. U.S.A. 109, 12776-12781. doi: 10.1073/pnas. 1202556109

Hsiao, E. Y., McBride, S. W., Hsien, S., Sharon, G., Hyde, E. R., McCue, T., et al. (2013). Microbiota modulate behavioral and physiological abnormalities associated with neurodevelopmental disorders. Cell 155, 1451-1463. doi: 10.1016/j.cell.2013.11.024

Hsu, H. J., Yen, C. H., Chen, C. K., Wu, I. W., Lee, C. C., Sun, C. Y., et al. (2013). Association between uremic toxins and depression in patients with chronic kidney disease undergoing maintenance hemodialysis. Gen. Hosp. Psychiatry 35, 23-27. doi: 10.1016/j.genhosppsych.2012.08.009

Kakita, A., Wakabayashi, K., Su, M., Piao, Y. S., and Takahashi, H. (2001). Experimentally induced leptomeningeal glioneuronal heterotopia and underlying cortical dysplasia of the lateral limbic area in rats treated transplacentally with methylmercury. J. Neuropathol. Exp. Neurol. 60, 768-777.

Kelly, S. J., Goodlett, C. R., and Hannigan, J. H. (2009). Animal models of fetal alcohol spectrum disorders: impact of the social environment. Dev. Disabil. Res. Rev. 15, 200-208. doi: 10.1002/ddrr.69

Kinast, K., Peeters, D., Kolk, S. M., Schubert, D., and Homberg, J. R. (2013). Genetic and pharmacological manipulations of the serotonergic system in early life: neurodevelopmental underpinnings of autism-related behavior. Front. Cell. Neurosci. 7:72. doi: 10.3389/fncel.2013.00072

Kriegstein, A. R., and Noctor, S. C. (2004).Patterns of neuronal migration in the embryonic cortex. Trends Neurosci. 27, 392-399. doi: 10.1016/j.tins.2004.05.001

Kriegstein, A., Noctor, S., and Martinez-Cerdeno, V. (2006). Patterns of neural stem and progenitor cell division may underlie evolutionary cortical expansion. Nat. Rev. Neurosci. 7, 883-890. doi: 10.1038/nrn2008

Lancaster, M. A., Renner, M., Martin, C. A., Wenzel, D., Bicknell, L. S., Hurles, M. E., et al. (2013). Cerebral organoids model human brain development and microcephaly. Nature 501, 373-379. doi: 10.1038/nature12517

Leung, A. K., and Sharp, P. A. (2010). MicroRNA functions in stress responses. Mol. Cell 40, 205-215. doi: 10.1016/j.molcel.2010.09.027

Levine, J. H., Lin, Y., and Elowitz, M. B. (2013). Functional roles of pulsing in genetic circuits. Science 342, 1193-1200. doi: 10.1126/science. 1239999 
Lewis, T. L. Jr., Courchet, J., and Polleux, F. (2013). Cell biology in neuroscience: cellular and molecular mechanisms underlying axon formation, growth, and branching. J. Cell Biol. 202, 837-848. doi: 10.1083/jcb.201 305098

Lidow, M. S., and Song, Z. M. (2001a). Effect of cocaine on cell proliferation in the cerebral wall of monkey fetuses. Cereb. Cortex 11, 545-551. doi: $10.1093 /$ cercor/11.6.545

Lidow, M. S., and Song, Z. M. (2001b). Primates exposed to cocaine in utero display reduced density and number of cerebral cortical neurons. J. Comp. Neurol. 435, 263-275. doi: 10.1002/cne.1028

Lindsley, T. A., Miller, M. W., Littner, Y., and Bearer, C. F. (2006). Signaling pathways regulating cell motility: a role in ethanol teratogenicity? Alcohol. Clin. Exp. Res. 30, 1445-1450. doi: 10.1111/j.1530-0277.2006.00173.x

Ling, M., Li, Y., Xu, Y., Pang, Y., Shen, L., Jiang, R., et al. (2012). Regulation of miRNA-21 by reactive oxygen species-activated ERK/NF-kappaB in arseniteinduced cell transformation. Free Radic. Biol. Med. 52, 1508-1518. doi: 10.1016/j.freeradbiomed.2012.02.020

Lipina, T. V., Zai, C., Hlousek, D., Roder, J. C., and Wong, A. H. (2013). Maternal immune activation during gestation interacts with Disc1 point mutation to exacerbate schizophrenia-related behaviors in mice. J. Neurosci. 33, 7654-7666. doi: 10.1523/JNEUROSCI.0091-13.2013

Mariani, J., Simonini, M. V., Palejev, D., Tomasini, L., Coppola, G., Szekely, A. M., et al. (2012). Modeling human cortical development in vitro using induced pluripotent stem cells. Proc. Natl. Acad. Sci. U.S.A. 109, 12770-12775. doi: 10.1073/pnas. 1202944109

Mattson, S. N., and Riley, E. P. (1998). A review of the neurobehavioral deficits in children with fetal alcohol syndrome or prenatal exposure to alcohol. Alcohol. Clin. Exp. Res. 22, 279-294. doi: 10.1111/j.1530-0277.1998.tb03651.x

Meldrum, S. J., Strunk, T., Currie, A., Prescott, S. L., Simmer, K., and Whitehouse, A. J. (2013). Autism spectrum disorder in children born pretermrole of exposure to perinatal inflammation. Front. Neurosci. 7:123. doi: $10.3389 /$ fnins.2013.00123

Meyer, U., Nyffeler, M., Engler, A., Urwyler, A., Schedlowski, M., Knuesel, I., et al. (2006). The time of prenatal immune challenge determines the specificity of inflammation-mediated brain and behavioral pathology. J. Neurosci. 26, 4752-4762. doi: 10.1523/JNEUROSCI.0099-06.2006

Millar, J. K., Wilson-Annan, J. C., Anderson, S., Christie, S., Taylor, M. S., Semple, C. A., et al. (2000). Disruption of two novel genes by a translocation co-segregating with schizophrenia. Hum. Mol. Genet. 9, 1415-1423. doi: 10.1093/hmg/9.9.1415

Miller, M. W., and Nowakowski, R. S. (1991). Effect of prenatal exposure to ethanol on the cell cycle kinetics and growth fraction in the proliferative zones of fetal rat cerebral cortex. Alcohol. Clin. Exp. Res. 15, 229-232. doi: 10.1111/j.1530-0277.1991.tb01861.x

Miranda, R. C. (2012). MicroRNAs and fetal brain development: implications for ethanol teratology during the second trimester period of neurogenesis. Front. Genet. 3:77. doi: 10.3389/fgene.2012.00077

Mitchell, A., Romano, G. H., Groisman, B., Yona, A., Dekel, E., Kupiec, M., et al. (2009). Adaptive prediction of environmental changes by microorganisms. Nature 460, 220-224. doi: 10.1038/nature08112

Mooney, S. M., and Varlinskaya, E. I. (2011). Acute prenatal exposure to ethanol and social behavior: effects of age, sex, and timing of exposure. Behav. Brain Res. 216, 358-364. doi: 10.1016/j.bbr.2010.08.014

Muralidharan, P., Sarmah, S., Zhou, F. C., and Marrs, J. A. (2013). Fetal Alcohol spectrum disorder (FASD) associated neural defects: complex mechanisms and potential therapeutic targets. Brain Sci. 3, 964-991. doi: 10.3390/brainsci3020964

Muramatsu, H., Katsuoka, F., Toide, K., Shimizu, Y., Furusako, S., and Yamamoto, M. (2013). Nrf2 deficiency leads to behavioral, neurochemical and transcriptional changes in mice. Genes Cells 18, 899-908. doi: 10.1111/gtc. 12083

Narasimhan, M., Mahimainathan, L., Rathinam, M. L., Riar, A. K., and Henderson, G. I. (2011). Overexpression of Nrf2 protects cerebral cortical neurons from ethanol-induced apoptotic death. Mol. Pharmacol. 80, 988-999. doi: 10.1124/mol.111.073262

Narasimhan, M., Riar, A. K., Rathinam, M. L., Vedpathak, D., Henderson, G., and Mahimainathan, L. (2014). Hydrogen peroxide responsive miR153 targets Nrf2/ARE cytoprotection in paraquat induced dopaminergic neurotoxicity. Toxicol. Lett. 228, 179-191. doi: 10.1016/j.toxlet.2014.05.020
Nollen, E. A., and Morimoto, R. I. (2002). Chaperoning signaling pathways: molecular chaperones as stress-sensing 'heat shock' proteins. J. Cell Sci. 115, 2809-2816.

Packer, A. N., Xing, Y., Harper, S. Q., Jones, L., and Davidson, B. L. (2008). The bifunctional microRNA miR-9/miR-9* regulates REST and CoREST and is downregulated in Huntington's disease. J. Neurosci. 28, 14341-14346. doi: 10.1523/JNEUROSCI.2390-08.2008

Pappalardo-Carter, D. L., Balaraman, S., Sathyan, P., Carter, E. S., Chen, W. J., and Miranda, R. C. (2013). Suppression and epigenetic regulation of MiR9 contributes to ethanol teratology: evidence from zebrafish and murine fetal neural stem cell models. Alcohol. Clin. Exp. Res. 37, 1657-1667. doi: 10.1111/acer.12139

Patten, A. R., Fontaine, C. J., and Christie, B. R. (2014). A comparison of the different animal models of fetal alcohol spectrum disorders and their use in studying complex behaviors. Front. Pediatr. 2:93. doi: 10.3389/fped.2014.00093

Patterson, P. H. (2011). Modeling autistic features in animals. Pediatr. Res. 69, 34R-40R. doi: 10.1203/PDR.0b013e318212b80f

Perry, W., Minassian, A., Lopez, B., Maron, L., and Lincoln, A. (2007). Sensorimotor gating deficits in adults with autism. Biol. Psychiatry 61, 482-486. doi: 10.1016/j.biopsych.2005.09.025

Pletnikov, M. V., Ayhan, Y., Nikolskaia, O., Xu, Y., Ovanesov, M. V., Huang, H., et al. (2008). Inducible expression of mutant human DISC1 in mice is associated with brain and behavioral abnormalities reminiscent of schizophrenia. Mol. Psychiatry 13, 173-186. doi: 10.1038/sj.mp.4002079

Purcell, S. M., Moran, J. L., Fromer, M., Ruderfer, D., Solovieff, N., Roussos, P., et al. (2014). A polygenic burden of rare disruptive mutations in schizophrenia. Nature 506, 185-190. doi: 10.1038/nature12975

Rakic, P. (2009). Evolution of the neocortex: a perspective from developmental biology. Nat. Rev. Neurosci. 10, 724-735. doi: 10.1038/nrn2719

Rakic, P., Ayoub, A. E., Breunig, J. J., and Dominguez, M. H. (2009). Dominguez, decision by division: making cortical maps. Trends Neurosci. 32, 291-301. doi: 10.1016/j.tins.2009.01.007

Ramkissoon, A., and Wells, P. G. (2013). Developmental role of nuclear factor E2-related factor 2 in mitigating methamphetamine fetal toxicity and postnatal neurodevelopmental deficits. Free Radic. Biol. Med. 65, 620-631. doi: 10.1016/j.freeradbiomed.2013.07.043

Roebuck, T. M., Mattson, S. N., and Riley, E. P. (1998). A review of the neuroanatomical findings in children with fetal alcohol syndrome or prenatal exposure to alcohol. Alcohol. Clin. Exp. Res. 22, 339-344. doi: 10.1111/j.15300277.1998.tb03658.x

Rojo, A. I., Rada, P., Egea, J., Rosa, A. O., Lopez, M. G., and Cuadrado, A. (2008a). Functional interference between glycogen synthase kinase- 3 beta and the transcription factor Nrf2 in protection against kainate-induced hippocampal cell death. Mol. Cell. Neurosci. 39, 125-132. doi: 10.1016/j.mcn.2008.06.007

Rojo, A. I., Sagarra, M. R., and Cuadrado, A. (2008b). GSK-3beta downregulates the transcription factor Nrf2 after oxidant damage: relevance to exposure of neuronal cells to oxidative stress. J. Neurochem. 105, 192-202. doi: 10.1111/j.1471-4159.2007.05124.x

Sathyan, P., Golden, H. B., and Miranda, R. C. (2007). Competing interactions between micro-RNAs determine neural progenitor survival and proliferation after ethanol exposure: evidence from an ex vivo model of the fetal cerebral cortical neuroepithelium. J. Neurosci. 27, 8546-8557. doi: 10.1523/JNEUROSCI.1269-07.2007

Schmitt, A., Malchow, B., Hasan, A., and Falkai, P. (2014). The impact of environmental factors in severe psychiatric disorders. Front. Neurosci. 8:19. doi: $10.3389 /$ fnins.2014.00019

Shi, Y., Kirwan, P., Smith, J., Robinson, H. P., and Livesey, F. J. (2012b). Human cerebral cortex development from pluripotent stem cells to functional excitatory synapses. Nat. Neurosci. 15, 477-486, S1. doi: 10.1038/nn.3041

Shi, Y., Zhang, X., Tang, X., Wang, P., Wang, H., and Wang, Y. (2012a). MiR-21 is continually elevated long-term in the brain after exposure to ionizing radiation. Radiat. Res. 177, 124-128. doi: 10.1667/RR2764.1

Shibata, M., Kurokawa, D., Nakao, H., Ohmura, T., and Aizawa, S. (2008). MicroRNA-9 modulates Cajal-Retzius cell differentiation by suppressing Foxg1 expression in mouse medial pallium. J. Neurosci. 28, 10415-10421. doi: 10.1523/JNEUROSCI.3219-08.2008

Shibata, M., Nakao, H., Kiyonari, H., Abe, T., and Aizawa, S. (2011). MicroRNA-9 regulates neurogenesis in mouse telencephalon by 
targeting multiple transcription factors. J. Neurosci. 31, 3407-3422. doi: 10.1523/JNEUROSCI.5085-10.2011

Smith, S. E., Li, J., Garbett, K., Mirnics, K., and Patterson, P. H. (2007). Maternal immune activation alters fetal brain development through interleukin-6. J. Neurosci. 27, 10695-10702. doi: 10.1523/JNEUROSCI.2178-07.2007

Smit-Rigter, L. A., Noorlander, C. W., von Oerthel, L., Chameau, P., Smidt, M. P., and van Hooft J. A. (2012). Prenatal fluoxetine exposure induces life-long serotonin 5-HT(3). receptor-dependent cortical abnormalities and anxiety-like behaviour. Neuropharmacology 62, 865-870. doi: 10.1016/j.neuropharm.2011.09.015

Solomon, P. R., Crider, A., Winkelman, J. W., Turi, A., Kamer, R. M., and Kaplan, L. J. (1981). Disrupted latent inhibition in the rat with chronic amphetamine or haloperidol-induced supersensitivity: relationship to schizophrenic attention disorder. Biol. Psychiatry 16, 519-537.

St Clair, D., Blackwood, D., Muir, W., Carothers, A., Walker, M., Spowart, G., et al. (1990). Association within a family of a balanced autosomal translocation with major mental illness. Lancet 336, 13-16. doi: 10.1016/0140-6736(90)91520-K

Stanwood, G. D., Washington, R. A., and Levitt, P. (2001). Identification of a sensitive period of prenatal cocaine exposure that alters the development of the anterior cingulate cortex. Cereb. Cortex 11, 430-440. doi: $10.1093 /$ cercor/11.5.430

Tal, T. L., Franzosa, J. A., Tilton, S. C., Philbrick, K. A., Iwaniec, U. T., Turner, R. T., et al. (2012). MicroRNAs control neurobehavioral development and function in zebrafish. FASEB J. 26, 1452-1461. doi: 10.1096/fj.11-194464

Thompson, B. L., Levitt, P., and Stanwood, G. D. (2009). Stanwood, Prenatal exposure to drugs: effects on brain development and implications for policy and education. Nat. Rev. Neurosci. 10, 303-312. doi: 10.1038/nrn2598

Tsai, P. C., Bake, S., Balaraman, S., Rawlings, J., Holgate, R. R., Dubois, D., et al. (2014). MiR-153 targets the nuclear factor-1 family and protects against teratogenic effects of ethanol exposure in fetal neural stem cells. Biol. Open 3, 741-758. doi: 10.1242/bio. 20147765

van Os, J., Kenis, G., and Rutten, B. P. (2010). The environment and schizophrenia. Nature 468, 203-212. doi: 10.1038/nature09563

Velasquez, J. C., Goeden, N., and Bonnin, A. (2013). Placental serotonin: implications for the developmental effects of SSRIs and maternal depression. Front. Cell. Neurosci. 7:47. doi: 10.3389/fncel.2013.00047

Wang, S., Yan, J. Y., Lo, Y. K., Carvey, P. M., and Ling, Z. (2009). Dopaminergic and serotoninergic deficiencies in young adult rats prenatally exposed to the bacterial lipopolysaccharide. Brain Res. 1265, 196-204. doi: 10.1016/j.brainres.2009.02.022

Weber, M., Baker, M. B., Moore, J. P., and Searles, C. D. (2010). MiR-21 is induced in endothelial cells by shear stress and modulates apoptosis and eNOS activity. Biochem. Biophys. Res. Commun. 393, 643-648. doi: 10.1016/j.bbrc.2010.02.045

Weinberger, D. R. (1987). Implications of normal brain development for the pathogenesis of schizophrenia. Arch. Gen. Psychiatry 44, 660-669. doi: 10.1001/archpsyc. 1987.01800190080012

Whitaker-Azmitia, P. M. (2001). Serotonin and brain development: role in human developmental diseases. Brain Res. Bull. 56, 479-485. doi: 10.1016/S03619230(01)00615-3
Whitford, K. L., Dijkhuizen, P., Polleux, F., and Ghosh, A. (2002). Molecular control of cortical dendrite development. Annu. Rev. Neurosci. 25, 127-149. doi: 10.1146/annurev.neuro.25.112701.142932

Wilson, S. E., and Cudd, T. A. (2011). Focus on: the use of animal models for the study of fetal alcohol spectrum disorders. Alcohol Res. Health 34, 92-98.

Wu, Z., He, B., He, J., and Mao, X. (2013). Upregulation of miR-153 promotes cell proliferation via downregulation of the PTEN tumor suppressor gene in human prostate cancer. Prostate 73, 596-604. doi: 10.1002/pros. 22600

Wynn, J. K., Dawson, M. E., Schell, A. M., McGee, M., Salveson, D., and Green, M. F. (2004). Prepulse facilitation and prepulse inhibition in schizophrenia patients and their unaffected siblings. Biol. Psychiatry 55, 518-523. doi: 10.1016/j.biopsych.2003.10.018

Yang, Z., Song, L., and Huang, C. (2009). Gadd45 proteins as critical signal transducers linking NF-kappaB to MAPK cascades. Curr. Cancer Drug Targets 9, 915-930. doi: 10.2174/156800909790 192383

Yano, M., Ohtsuka, T., and Okano, H. (2015). RNA-binding protein research with transcriptome-wide technologies in neural development. Cell Tissue Res. 359, 135-144. doi: 10.1007/s00441-014-1923-8

Yoo, A. S., Staahl, B. T., Chen, L., and Crabtree, G. R. (2009). MicroRNA-mediated switching of chromatin-remodelling complexes in neural development. Nature 460, 642-646. doi: 10.1038/nature08139

Young, J. W., Locke, J. C., and Elowitz, M. B. (2013). Rate of environmental change determines stress response specificity. Proc. Natl. Acad. Sci. U.S.A. 110, 4140-4145. doi: 10.1073/pnas.1213060110

Zhao, C., Sun, G., Li, S., and Shi, Y. (2009). A feedback regulatory loop involving microRNA-9 and nuclear receptor TLX in neural stem cell fate determination. Nat. Struct. Mol. Biol. 16, 365-371. doi: 10.1038/nsmb.1576

Zhong, Z., Dong, Z., Yang, L., and Gong, Z. (2012). miR-21 induces cell cycle at $\mathrm{S}$ phase and modulates cell proliferation by down-regulating hMSH2 in lung cancer. J. Cancer Res. Clin. Oncol. 138, 1781-1788. doi: 10.1007/s00432-012$1287-\mathrm{y}$

Zucchi, F. C., Yao, Y., Ward, I. D., Ilnytskyy, Y., Olson, D. M., Benzies, K., et al. (2013). Maternal stress induces epigenetic signatures of psychiatric and neurological diseases in the offspring. PLOS ONE 8:e56967. doi: 10.1371/journal.pone.0056967

Conflict of Interest Statement: The authors declare that the research was conducted in the absence of any commercial or financial relationships that could be construed as a potential conflict of interest.

Copyright (c) 2015 Ishii and Hashimoto-Torii. This is an open-access article distributed under the terms of the Creative Commons Attribution License (CC BY). The use, distribution or reproduction in other forums is permitted, provided the original author(s) or licensor are credited and that the original publication in this journal is cited, in accordance with accepted academic practice. No use, distribution or reproduction is permitted which does not comply with these terms. 